\title{
PENDIDIKAN SAINS BERBASIS SPIRITUALITAS DALAM PERSPEKTIF AL-QUR'AN
}

\author{
H. Zamakhsyari Abdul Majid \\ UIN Syarif Hidayatullah Jakarta, DPK. Pascasarjana UIN Jakarta \\ Jl. Ir. H. Juanda Ciputat. Tanggerang Selatan \\ Hp: 081318440028, Email: zamakhsyari_am@yahoo.co.id
}

\begin{abstract}
Throughout 2006, Indonesia was rocked by a phenomenal work by Dr. Masaru Emoto about the true power of water. In his book entitled The True Power of Water, Emoto managed to show scientifically the results of his research that when whispered or written good words and certain prayers turn into beautiful crystals that function as "Hado" for human health.

The Qur'an, though, was created more than fourteen years ago as a human guideline for achieving the salvation of the world and the hereafter. This is proven by several discoveries, one of which is Dr. Masaru Emoto who succeeded in creating "Hado" as a scientific finding that uses water media. For Muslims, the belief in the miracles of the Qur'an given to mankind itself opens the eyes of the heart to continue to hold fast to the Qur'an. Besides the greatness of the Qur'an as a source of knowledge that can be proven based on in-depth study of scientific science.

Thus, the Qur'an provides knowledge about the principles of science and education, which are always associated with knowledge of metaphysics, morality and spirituality. The human method in getting knowledge is very relative to get it, but all is done not apart from the source that is essential that is the source of knowledge from God Almighty. That way, this is what is in the education process.
\end{abstract}




\section{A. Pendahuluan}

Sepanjang tahun 2006, Indonesia diguncang sebuah karya fenomenal Dr. Masaru Emoto tentang kekuatan sejati air. Dalam bukunya yang berjudul The True Power of Water, Emoto berhasil menunjukan secara ilmiah hasil penelitianya bahwa air jika dibisikan atau dituliskan kata-kata yang baik dan doa-doa tertentu berubah menjadi kristal-kristal yang indah sehingga berfungsi sebagai "Hado" untuk kesehatan manusia.

Temuan Dr. Masaru Emoto itu memperlihatkan adanya keterkaitan erat antara alam dan Tuhan sekaligus membuka paradigma baru tentang interaksi spritual dan material. Betapa penemuan ilmiah ini menjadi rentetan sejarah atau kebenaran ajaran Al-Qur'an, karena berhasil menyingkap rahasia Al-Qur'an bahwa air ialah sumber kehidupan bagi mahkluk semesta alam. Dalam Al-Qur'an surat al-Anbiya' ayat 30 Allah swt berfirman,"... Dan dari air Kami jadikan segala sesuatu yang hidup. Maka mengapakah mereka tiada juga beriman".

Dalam perspektif filsafat sains, karya Dr. Masatu Emoto ini adalah sebuah terobosan gemilang yang mampu menyatukan temuan sains metafisika ke dalam samudra spritual (agama). Hasil pengamatanya yang jeli, cermat dan inovatif terhadap karakter air yang "sesungguhnya" mengantarkan kita masuk alam baru pemahaman tentang Kemahacerdasan Allah, Tuhan Sang Pencipta jagat Raya, yang terdistribusi secara sistematis dan proporsional di setiap elemen kealamsemestaan.

Sains merupakan kajian ilmiah yang terdiri dari keutamaan ilmu-ilmu secara objektif lebih memprioritaskan pengamatan dan penelitian secara ilmiah. Hasil ilmiah ini lah yang dijadikan manusia sebagai wujud eksistensi manusia dalam merubah paradigma seseorang tentang ilmu pengetahuan.

Al-Qur'an kendatinya telah diciptakan lebih dari empat belas tahun yang lalu sebagai pedoman manusia untuk mencapai keselamatan dunia dan 
akhirat. Hal ini dibuktikan oleh beberapa penemuan salah satunya Dr. Masaru Emoto yang berhasil menciptakan "Hado" sebagai temuan ilmiah yang mengunakan media air. Bagi umat Islam, keyakinan akan mukjizat Al-Qur'an yang diberikan kepada manusia itu sendiri membuka mata hati untuk tetap berpegang teguh kepada Al-Qur'an. Di sampimg kebesaran Al-Qur'an sebagai sumber keilmuan yang dapat dibuktikan berdasarkan kajian sains ilmu pengetahuan secara mendalam.

Fenomena penemuan keajaiban air oleh Emoto, merupakan dedikasi keilmuan yang berhasil diformulasikan oleh penemu asal Jepang sebagai penemuan yang mengagumkan. Bagaimanapun, menemuan ini patut diberikan apresiasi yang sebenar-besarnya sebagai proses mengilmiahkan kajian Al-Qur'an ke dalam kehidupan manusia. Dengan begitu, Al-Qur'an akan dijadikan sebagai mukjizat bagi menusia atas kebenaran-Nya.

Menurut Bucaille, seorang ilmuan berkebangsaan Prancis dalam bukunya La Bible, La Coran et La Science menyetakan, Al-Qur'an berbeda dengan Bibel (Kitab Lama dan Perjanjian Baru). Hal ini memiliki kontradiksi yang terjadi pada Bibel bila dihubungkan dengan laju perkembangan Sains Modern. Sedangkan Al-Qur'an, semua ajaranya sangat relevan dengan sains modern. Seperti halnya pembiacaraan tentang bumi, hewan, tumbuhtumbuhan, dan kelahiran tentang manusia, ternyata semuanya itu merupakan masalah ilmiah yang terjadi dalam kehidupan manusia saat ini.

Konsep sains modern telah ditemukan para ilmuan abad ini. AlQur'an yang sudah lebih dahulu adanya. Sebab Al-Qur'an telah diturunkan sejak 1400 tahun silam, di dalamnya membahas banyak ilmu pengetahuan (sains), akan tetapi baru kali ini formulasi sains telah dibuktikan oleh para ilmuan.

Sementara itu, Osman Bakar, seorang Profesor Emiretus dalam Filsafat Sains dan juga Peneliti Senior International Islamic University of 
Malaya, menegaskan bahwa Al-Qur'an merupakan sumber intelektualitas dan spritualitas. Ia adalah basis bukan hanya bagi agama dan pengetahuan spritual tetapi bagi semua jenis pengetahuan. Ia merupakan sumber utama inspirasi pandangan muslim tentang keterpaduan sains dan pengetahuan spritual (agama). Gagasan keterpaduan ini merupakan konsekwensi dari gagasan keterpaduan semua jenis pengetahuan, yang pada dasarnya diturunkan dari prinsip Keesaan Tuhan dalam konteks ketauhidan yang ditetapkan untuk menusia.

Manusia sebagai objek pengetahuan merupakan indikasi keutamaan dalam menjelaskan konten ilmu pengetahuan. Hal ini merupakan wujud pengamalan manusia dari proses perkembangan pola intelektual manusia kepada manusia itu sendiri dan proses spritualitas manusia kepada Tuhan Yang Maha Esa.

Pendidikan merupakan proses dalam membina dan mempengaruhi tingkat lanjut pengetahuan manusia. Wujud pengetahuan yang terdapat dalam proses pendidikan tidak lepas dari bagaimana mengembangkan pola pikir (Kognitif) memiliki jiwa positif (afektif) dan pengamalan tindakan (Psikomotor) sebagai prinsip utama pendidikan. Terkait dengan sains, hal ini sangat erat kaitanya dengan proses pendidikan. Pendidikan muncul dari perkembangan sains, dan sains akan berkembang jika pola pendidikannya relevan dengan kondisi saat ini.

Dengan demikian, Al-Qur'an memberikan pengetahuan tentang prinsip-prinsip sains dan pendidikan, yang selalu dikaitkan dengan pengetahuan metafisika, moralitas dan spritualitas. Metode manusia dalam mendapatkan ilmu pengetahuan sangat relatif untuk mendapatkanya, akan tetapi semua dilakukan tidak lepas dari sumber yang hakiki yaitu sumber pengetahuan dari Tuhan Yang Maha Esa. Dengan begitu, inilah yang terdapat dalam proses pendidikan. 


\section{Pendidikan Sains Berbasis Spiritualitas dalam Perspektif al-Qur'an}

Tulisan ini bermaksud akan menyikapi bukti pendidikan sains metafisika terpadu dalam perspektif Al-Qur'an. Serta berusaha memaksimalkan pendidikan sians modern dengan pengetahuan spritualitas berdasarkan kajian Ilmu Al-Qur'an dalam kehidupan manusia.

\section{B. Kerangka Konseptual Pendidikan Sains dalam perspektif Spritualitas}

Sebelum kita menelisik lebih jauh tentang kerangka konseptual pendidikan sains dalam perspektif Spriual, maka terlebih dahulu akan diuraikan tentang hakikat pendidikan sains. Sehingga diperoleh pemahaman yang utuh tentang apa sebenarnya yang dimaksud dengan sains dalam perspektif spritual.

Menurut kamus besar Webster's New World Dictionary (1996:135), sains berasal dari bahasa Latin, scire yang bearti mengetahui. Kemudian dalam perkembanganya pemaknaan sains dipahami sebagai pengetahuan yang sistematis yang berasal dari observasi, kajian dan percobaan yang dilakukan untuk menentukan sifat dasar atau perinsip dari apa yang dikaji.

Ali Syari'ati (1998:16), seorang intelektual Muslim "Raksasa" dari Iran berpendapat: "Science is knowledge of man about the physical world and its phenomena. It is man's mental image of the secret. It is discovery of some relationship, of a principle, of quality, of a characteristic in man, in nature, or in other entities". Maksudnya, sains adalah pengetahuan manusia tentang dunia fisik dan fenomenanya. Sains merupakan gambaran mental manusia dalam menyingkap berbagai rahasia. Sains bertujuan untuk menemukan hubungan, prinsip-prinsip dan karakteristik tentang manusia, alam dan entitas-entitasnya.

Sains telah dengan seksama dan mendalam mempelajari segala aspek tentang dunia fisik sehingga ia merupakan kajian yang komprehensif tentang 
alam semesta (Mulyadhi Kartanegara, 2003:8). Sehingga sains merupakan pengetahuan yang sistematis tentang alam dan dunia fisik.

Dengan berbagai pendapat di atas dapat kita simpulkan, bahwa sains merupakan kumpulan sudut pandang manusia secara mendasar, menyeluruh dan kompleks dengan kualitas manusia sebagai kajian fenomena tertentu. Sains adalah pengetahuan yang diperoleh melalui metode sains (scientific methode), yakni atas dasar observasi (bayani), percobaan dan demonstran (burhani) serta intuisi (irfani), yang masing-masing bersumber pada indera, akal dan hati.

Selain itu, pembahasan tentang pengertian pendidikan tidak dapat dipisahkan dari Al-Qur'an. Tiga prosedur untuk menggali hakikat ilmu pendidikan dalam Al-Qur'an diantaranya;

1. Memilih istilah-istilah kunci (key term) dari kosakata Al-Qur'an, yang dianggap sebagai weltanschauung dari Al-Qur'an. Seperti tarbiyah, ta'lim, ta'dib, riyadhah, irsyad dan tadris.

2. Menentukan makna pokok dan makna kotekstual

3. Menyimpulkan weltanschauung dengan menyajikan konsep-konsep dalam keutuhan. Kesimpulan ini dapat melahirkan pengertian terminoligi atau istilah dalam pendidikan Islam (A.Heris Hermawan, 2013: 1-2).

Pada saat ini pemakaian istilah yang paling populer yang digunakan orang adalah "tarbiyah" karena istilah ini mencakup keseluruhan kegiatan pendidikan. Terbiyah merupakan usaha untuk mempersiapkan individu untuk kehidupan yang lebih sempurna, sistematis dalam berpikir, memiliki ketajaman intuisi, memiliki jiwa toleransi pada orang lain dan berbudi luhur. Dengan demikian maka istilah pendidikan Islam disebut Tarbiyah Islamiyah.

Sedangkan Pendidikan dalam Undang-undang 20 Tahun 2003 menjelaskan tentang pengertian pendidikan sebagai berikut: 
Pendidikan Sains Berbasis Spiritualitas dalam Perspektif al-Qur'an

"Pendidikan adalah usaha sadar dan terencana untuk mewujudkan suasana belajar dan proses pembelajaran agar peserta didik secara aktif mengembangkan potensi dirinyauntuk memiliki kekuatan spiritual keagamaan, pengendalian diri, kepribadian, kecerdasan, akhlak mulia, serta keterampilan yang diperlukan dirinya, masyarakat, bangsa dan negara".

Pendidikan pada hakikatnya merupakan proses tranformasi pengetahuan kepada objek dari pendidikan, karena pendidikan menjadi solusi utama dalam mengembangkan tujuan proses mutu yang berkualitas.

Tujuan pendidikan merupakan konsep luas dalam menentukan proses mutu sebagai langkah strategi pendidikan. Adapun tujuan tersebut sudah terkamtub dalam Sisitem Pendidikan Nasional sebagai berikut:

"Berkembangnya potensi peserta didik agar menjadi manusia yang beriman dan bertakwa kepadaTuhan Yang Maha Esa, berakhlak mulia, sehat, berilmu, cakap, kreatif, mandiri, dan menjadi warganegara yang demokratis serta bertanggung jawab" (SISDIKNAS, 20 Tahun 2003: Pasal 3).

Dengan demikian, pendidikan sangat mengutamakan tingkat Ketuhanan sebagai prioritas diri keilmuan manusia. wujudi prioritas keilmuan manusia di dasari oleh tingkat Ketuhanan yang akan menghasilkan kekuatan spritual sebagai integritas manusia sebagai mahkluk.

Fenomena ini membawa paradigma kepada manusia, dalam pandangan sains, yang menjadikan dasar asumsi pengetahuan dimulai dari kecerdasan (Intelektual) manusia dalam memahami fenomena yang terjadi. Manusia telah kehilangan dimensi spiritualnya. Manusia dipandang sematamata sebagai makhluk fisik dengan sistem saraf yang sangat rumit, tetapi 
yang tidak cukup menghasilkan jiwa sebagai sebuah substansi imateriil (Mulyadhi Kartanegara, 2003: 9).

Pendidikan pada dasarnya memiliki dua aspek, yaitu membantu dan menolong. Sedangkan ilmu sains, sangat dekat dengan pengetahuan yang di uji secara ilmiah. Keduanya memiliki persamaan, yaitu substansi manusia dalam mencapai hakikat ilmu ditunjukan dalam formulasi pendidikan dan konsepsi sains yang di dasari oleh tingkat spiritualitas yang tinggi sebagai wujud pengembangan pengetahuan yang dapat membantu dan menolong manusia dalam memahami kaedah keilmuan.

\section{Konseptual Spritualitas sebagai dasar Sains Modern}

Spritualitas adalah keyakinan dalam hubunganya dengan Tuhan Yang Maha Kuasa dan Maha Pencipta, sebagai kontak interaksi kepada Sang Pencipta. Hal ini di dasari atas keinginan manusia dalam mendapatkan dan mengembangkan ilmu pengetahuan tidak lepas dari rasa spritualitas yang tinggi untuk mencapai hakikat keilmuan-Nya.

Memiliki rasa spritualitas merupakan pernyataan pengetahuan tentang realitas. Orang Islam emmandang berbagai sains, ilmu alam, ilmu sosial dan lainya sebagai beragam bukti yang menujukan atas keberadaan-Nya dan kekuasaan-Nya.

Semangat ilmiah para ilmuan muslim pada masa lampau pada kenyataanya mengalir dari kesadaran mereka akan tingkat spiriualnya. Para ilmuwan muslim mulai menaruh perhatian pada ilmu-ilmu alam secara serius sejak abad ke- 3 Hijriah (abad 9 Masehi). Tetapi pada saat itu mereka telah memiliki sikap ilmiah dan kerangka berpikir ilmiah yang mereka warisi dari ilmu-ilmu agama, yang bersumber dari ajaran spiritual.

Melalui keyakinan dan pemahaman itulah, pada abad pertengahan umat Islam telah membuktikan eksistensinya dengan memiliki ilmuwan- 
ilmuwan muslim ternama dalam berbagai bidang keilmuan, antara lain: AlFarabi, Al-Ghazali, Al-Kindi, Ibnu Sina, Ibnu Rusyd, Ibnu Khaldun, Ar-Razi, Al-Biruni, Ibnu al-Haytsam, Az-Zahrawi, Al- Khawarizmi, Al-Jahid, Ikhwan ash-Shofa, Nashirudin ath-Thusi, Quthbuddin asy-Syirazi, Kamaluddin alfarisi dan lainya (Amirullah Syarbini, 2011: 77).

Para ilmuwan muslim berpendapat, bahwa rasa spiritual ialah asal terciptanya ilmu pengetahuan. Selaras dengan prinip Islam, orang muslim menyakini bahwa Allah-lah yang Mutlak dan bahwa semua yang lain adalah nisbi. Sebagai kebenaran Mutlak (Al-Haqq), Allah merupakan sumber dari semua kebenaran lain, yang mengakui adanya suatu hierarki atau tingkatan kenisbian.

Dengan demikian, benarkah konsep spiritual menjadi dasar terciptanya sains modern? Berikut pandangan Al-Qur'an dalam menjelaskan ilmu sains berbasis spiritual :

Pertama, Al-Qur'an menjelaskan bahwa Allah swt menciptakan manusia dan mahkluk lainya semata-mata untuk beribadah kepada-Nya: "Dan tidaklah Aku menciptakan Jin dan manusia kecuali untuk beribadah kepada-Ku" (Q.S Adz-Dzariyat: 56). Dengan demikian, hakikat ilmu pengetahuan, sains dan tekhnologi yang dikembangkan manusia adalah harus senantiasa dalam rangka beribadah kepada-Nya.

Kedua, sumber ilmu pengetahuan pada hakikatnya diciptakan oleh Allah swt, baik yang melalui wahyu (ayat qauliyah), maupun yang melalui hamparan alam semesta (ayat kauniyah). Oleh karena itu, segala pengetahuan yang dimiliki manusia pada hakikatnya adalah berasal dari ilmu Allah yang harus disyukuri oleh manusia.

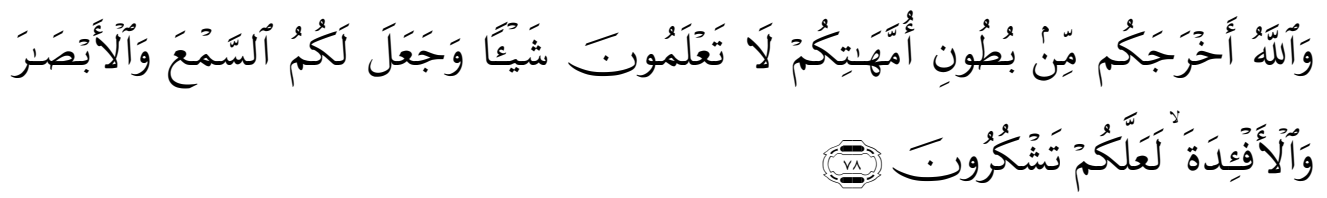


Artinya: "Dan Allah mengeluarkan kamu dari perut ibumu dalam Keadaan tidak mengetahui sesuatupun, dan Dia memberi kamu pendengaran, penglihatan dan hati, agar kamu bersyukur". (Q.S An-Nahl [16]: 78).

Ketiga, Al-Qur'an berbicara tentang alam raya dan fenomenanya, terlihat jelas bahwa pembicaraanya selalu dikaitkan dengan kebenaran dan kekuasaan Allah. Di dalam Al-Qur'an surat Ath-Thalaq 12, Allah memberikan penjelasan bahwa hakikat sains adalah sebagai bukti akan kekuasaan dan kebesaran-Nya:

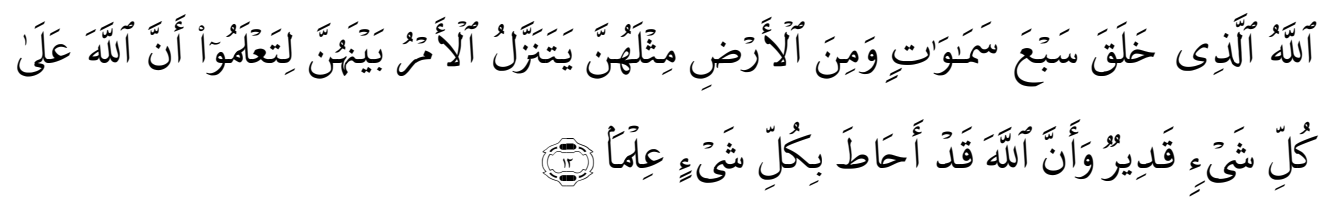

Artinya: "Allah-lah yang menciptakan tujuh langit dan seperti itu pula bumi. perintah Allah Berlaku padanya, agar kamu mengetahui bahwasanya Allah Maha Kuasa atas segala sesuatu, dan Sesungguhnya Allah ilmu-Nya benar-benar meliputi segala sesuatu". (Ath-Thalaq [65]: 12).

Dengan demikian, Al-Qur'an bukanlah kitab ilmu pengetahuan, melainkan kitab yang menjelaskan dan memberikan ruang kepada manusia untuk tetap berpegang teguh kepada kitab-Nya dengan memformulasikan kajian pengetahuan berdasarkan kajian Ilmu Al-Qur'an.

Quraish Shihab (2001) juga menentang semboyan "Ilmu untuk Ilmu" dan dianggap tidak dikenal dalam ajaran Islam. Sains sekali lagi tidak bebas dari nilai. Melainkan sains cukup sarat akan nilai, karena hal ini mendukung pencitraan yang sempurna untuk manusia. manusia bukanlah makhluk biologis semata yang melakukan proses mekanisme, sebagaimana mesin, tetapi dia adalah unik, dengan akal, rasa dan jiwanya yang diperintah Tuhan untuk menjalankan misinya untuk menjadi ham Allah dan menjadi khalifah Allah di muka bumi ini. 
Allah swt menurunkan Al-Qur'an pada empat belas abad yang lalu. Al-Qur'an bukan buku ilmiah, tetapi kitab ini mencakup beberapa penjelasan ilmiah yang tidak pernah bertentangan dengan temuan-temuan sains modern. Fakta-fakta tertentu diungkapkan dalam penemuan kajian tekhnologi abad ke-20 itu sebenarnya telah diungkapkan dalam Al-Qur'an sejak empat belas abad silam. Ini menunjukan bahwa terdapat titik temu sains dengan agama yang didalamnya terdapat kajian spritual. Dengan demikian, Al-Qur'an memandang terdapat hubungan erat antara sains dan spritual dalam agama, serta keduanya tidak terjadi saling kontradiksi.

Al-Qur'an bukanlah kitab sains. Tetapi ia memberikan pengetahuan tentang dasar dan prinsip sains, yang selalu dikaitkan dengan pengetahuan metafisik dan spiritual. Tanda-tanda tersebut, telah dibuktikan Al-Qur'an lewat wahyu pertama yang diturunkan Allah kepada Nabi Muhammad saw:

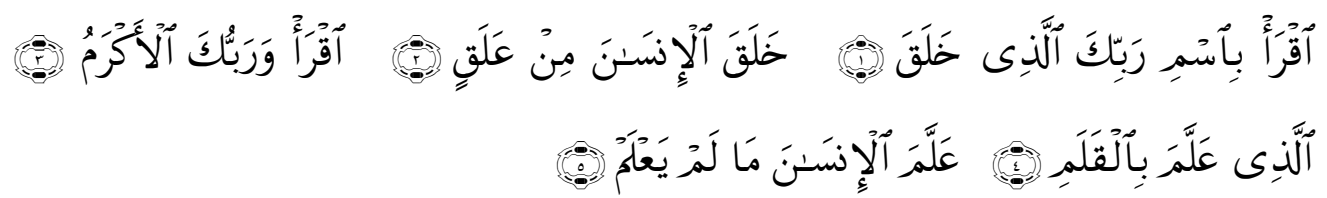

Artinya: "Bacalah dengan (menyebut) nama Tuhanmu yang Menciptakan, Dia telah menciptakan manusia dari segumpal darah., Bacalah, dan Tuhanmulah yang Maha pemurah, yang mengajar (manusia) dengan perantaran kalam, Dia mengajar kepada manusia apa yang tidak diketahuinya”. (Q.S Al-Alaq [96]: 1-5).

Untuk menulusuri pandangna Al-Qur'an tentang sains, mau tidak mau, mengundang kita menengok sekian banyak ayat Al-Qur'an yang berbicara tentang alam raya. Menurut para ulama, terdapat sekitar 750 ayat Al-Qur'an yang berbicara tentang alam materi dan fenomenanya. Dan menurut para peneliti sementara, tidak kurang dari 28 ilmu terdapat dalam Al-Qur'an (Ghulsyani, 1998:62). Hal ini menunjukan tidak pernah bertentangan Al-Qur'an dengan sains modern. Bahkan belakangan ini, begitu 
banyak penemuan-penemuan ilmiah yang juga ditemukan konsepya dalam Al-Qur'an.

Ada banyak penemuan sains mutakhir yang menyingkap kebenaran kitab suci terakhir yang diturunkan kepada Nabi Muhammad saw ini, antara lain:

Pada tahun 1925, seorang ahli astronomi Amerika, Edwin Hubble memberikan bukti penelitian, bahwa ternyata alam semesta ini menjadi ada secara tiba-tiba setelah sebelumnya tidak ada. Teori ini disebut sebagai teori Ledakan Dasyat (Big Bang), yang berpandangan bahwa alam semesta ini pada awalnya terjadi dengan peledakan. Teori ledakan dasyat ini menunjukan bahwa mulainya, semua objek di alam semesta merupakan satu bagian yang kemudan terpisah-pisah. Kenyataan yang ditunjukan oleh teori Ledakan Dashyat ini, dinyatakan Al-Qur'an pada empat belas abad yang lalu, ketika manusia memiliki pengetahuan yang amat terbatas tentang alam semesta.

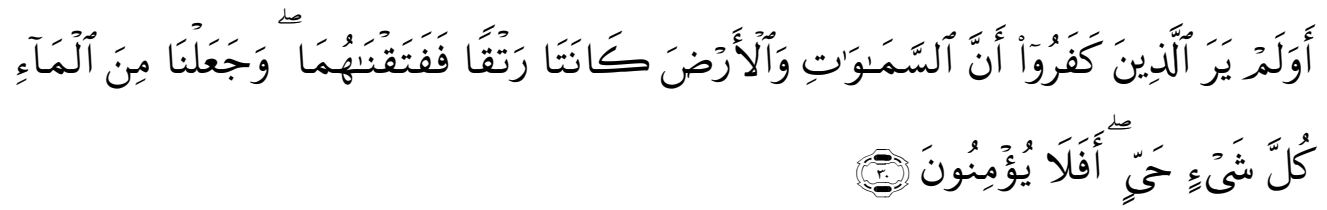

Artinya: "Dan Apakah orang-orang yang kafir tidak mengetahui bahwasanya langit dan bumi itu keduanya dahulu adalah suatu yang padu, kemudian Kami pisahkan antara keduanya. dan dari air Kami jadikan segala sesuatu yang hidup. Maka Mengapakah mereka tiada juga beriman?”. (Q.S Al-Anbiya [21]: 30).

Prof. Dr. Keith Moore, seorang Profesor Ilmu Janin dan Pimpinan Departement Anatomy di Universitas Terotto, Canada. Setelah berhati hati menguji terjemahan Al-Qur'an, ia tidak bisa berkomentar banyak dan hanya berkata bahwa informasi tentang ilmu janin yang tersebut dalam Al-Qur'an telah menjelaskan dengan sangat jelas dan sempurna. Al-Qur'an sangat cocok dengan penemuan-penemuan modern di bidang ilmu janin. Moore memberikan bukti bahwa jenis kelamin suatu janini ditentukan oleh sifat 
alami sperma dan bukan telur. Jenis kelamin anak wanita atau laki-laki bergantung pada pasangan kromosom ke-23, adalah XX dan XY berturutturut.

Penentuan kemalin terutama pada pembuahan dan bergantung pada tipe kromosom kelamin sperma yang membuahi satu telur. Jika yang membuahi telur adalah X, janin itu adalah wanita: dan jika sperma adalah Y, maka janin itu adalah laki-laki. Dalam suatu ayat dinyatakan bahwa kepriaan atau kewanitaan itu tercipta dari air mani, dengan kata lain, sumber jenis kelamin itu bukan prempuan malainkan laki-laki

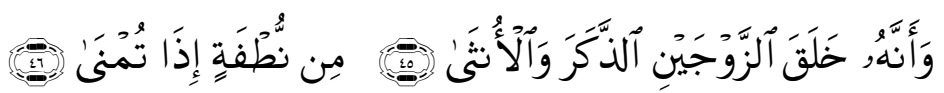

Artinya: "Dan bahwasanya Dialah yang menciptakan berpasangpasangan pria dan wanita, dari air mani, apabila dipancarkan". (Q.S AnNajm [53: 45-46).

Berbagai pembuktian ilmiah di atas menunjukan bahwa Al-Qur'an merupakan kitab ilahi yang tidak pernah bertentangan dengan realitas perkembangan sains dan tekhnologi. Pembuktian ini sekaligus meruntuhkan filsafat materialisme yang beranggapan bahwa alam semesta ada dengan sendirinya tanpa diciptakan. Filsfat inilah yang mendukung atheisme. Bentuk anggapan tidak ada hikmah apapun yang dapat diperoleh dari Tuhan meniptakan alam semesta.

\section{Penutup}

Salah satu fenomena keajaiban yang paling populer dan menakjubkan dewasa ini adalah sejumlah pernyataan Al-Qur'an berkaitan dengan sains, dimana pada masa diturunkannya Al-Qur'an 1400 yang lalu, Nabi Muhammad dan orang-orang yang hidup di masa itu, belum mengetahui masalah ini. 
Dalam tulisan ini telah menjelaskan informasi tentang sains yang dibeberkan Al-Qur'an, ternyata benar-benar bertepatan dengan penemuan sains modern. Hal ini menunjukan bahwa antara pendidikan sains berbasis spiritual dalam perspektif Al-Qur'an merupakan saru kesatuan (integral) yang utuh dan tidak bisa dipisahkan. Dengan demikian, integrasi antara sains dan rasa spiritual dalam perspektif Al-Qur'an adalah sebuah keniscayaan

Oleh karena itu, ketika kita menemukan pertentangan antara ayat AlQur'an dan sains modern, maka umat Islam harus mengambil ayat Al-Qur'an tanpa ragu sebagai tujukan yang paling shaheh. Sebab, menolak Al-Qur'an atau meragukan kebenaran-Nya adalah sama saja dengan menolak dan meragunkan ilmu Allah.

Sebagai penutup, meskipun ilmiah dan isyarat sains terdapat dalam Al-Qur'an sebagai bukti kemukjizatanya, kita harus tetap dan meletakan pada kedudukan paling benar serta sesuai, dan membutuhkan metodologi yang benar dalam menginterpretasikan ayat-ayat Al-Qur'an. Oleh karena itu, dengan penuh hati-hati, dalam meneliti dan membuktikan bahwa Al-Qur'an memang mengandung dan menyiratkan sejumlah fakta ilmiah.

Wallahu a'la bish Shawwab!

\section{DAFTAR PUSTAKA}

Ali Syari'ati. 1998. Membangun Masa Depan Islam. Bandung: Mizan.

Amirulloh Syarbini. 2008. Training of Syahril Qur'an. Bandung. Cahaya Publishing.

A.Heris Hermawan. 2013. Ilmu Pendidikan Islam. Bandung. Cv Insan Mandiri.

Ismail Raj'i al-Faruqi. 1982. Tauhid: its Implicaions for Thought and Life.

Viginia: International Institute of Islamic Thought.

Mahdi Ghulsyani. 1998. Filsafat Sains Menurut Al-Qur'an. Bandung: Mizan 
Pendidikan Sains Berbasis Spiritualitas dalam Perspektif al-Qur'an

Masaru Emoto. 2006. The True Power of Water: Hikmah Air Dalam Olah Jiwa. Bandung: MQ Publishing.

Maurice Bucaille. 2001. Bibel, Qur'an dan Sains Modern. Jakarta: Bulan Bintang.

M. Quraish Shihab. 2001. Membumikan Al-Qur'an Fungsi dan Peran Wahyu dalam Kehidupan Masyarakat. Bandung: Mizan

Mulyadhi Kartanegara. 2003. Menyibuk Tirai Kejahilan: Penghantar Epistimologi Islam. Bandung: Mizan

Syaikh Abdullah M. Al-Ruhaili. 2008. Al-Quran The Ultimate Truth: Menyikap Kebenaran Kitab Suci Terakhir Melalui Penemuan Sains Mutakhir. Jakarta: Mirqat Publishing.

Yoroshi Haryadi dan Azaki Karni. 2007. The Untrue Power of Water: Fakta dan Mitos Temuan Masaru Emoto. Jakarta: Penerbit Hikmah.

Zamakhsyari Abdul Majid. 2014. Metodologi Ayat-Ayat Hukum, dan Tafsir Al-Munir Karya Wahbah Al-Zuhaili. Depok. Indie Publishing.

Zakir Naik dan Gary Miller. 2009. Keajaiban Al-Qur'an dalam Temuan Sains Modern. Yogyakarta: Penerbit Media Ilmu. 